\title{
Use-Dependent AMPA Receptor Block Reveals Segregation of Spontaneous and Evoked Glutamatergic Neurotransmission
}

\author{
Yildirim Sara, ${ }^{1,4}$ Manjot Bal, ${ }^{1}$ Megumi Adachi, ${ }^{2}$ Lisa M. Monteggia, ${ }^{2}$ and Ege T. Kavalali ${ }^{1,3}$ \\ Departments of ${ }^{1}$ Neuroscience, ${ }^{2}$ Psychiatry, and ${ }^{3}$ Physiology, University of Texas Southwestern Medical Center, Dallas, Texas 75390-9111, and ${ }^{4}$ Department \\ of Pharmacology, Hacettepe University Faculty of Medicine, Sihhiye Ankara, 06100, Turkey
}

Earlier findings had suggested that spontaneous and evoked glutamate release activates non-overlapping populations of NMDA receptors. Here, we evaluated whether AMPA receptor populations activated by spontaneous and evoked release show a similar segregation. To track the receptors involved in spontaneous or evoked neurotransmission, we used a polyamine agent, philanthotoxin, that selectively blocks AMPA receptors lacking GluR2 subunits in a use-dependent manner. In hippocampal neurons obtained from GluR2-deficient mice, philanthotoxin application decreased AMPA-receptor-mediated spontaneous miniature EPSCs (AMPA-mEPSCs) down to 20\% of their initial level within $5 \mathrm{~min}$. In contrast, the same philanthotoxin application at rest decreased the subsequent AMPA-receptormediated evoked EPSCs (eEPSCs) only down to $80 \%$ of their initial value. A 10 -min-long perfusion of philanthotoxin further decreased AMPA-eEPSC amplitudes to $60 \%$ of their initial magnitude, which remained substantially higher than the level of AMPA-mEPSC block achieved within $5 \mathrm{~min}$. Finally, stimulation after removal of philanthotoxin resulted in reversal of AMPA-eEPSC block, verifying strict use dependence of philanthotoxin. These results support the notion that spontaneous and evoked neurotransmission activate distinct sets of AMPA receptors and bolster the hypothesis that synapses harbor separate microdomains of evoked and spontaneous signaling.

\section{Introduction}

Spontaneous neurotransmission is a ubiquitous property of all synaptic networks (Fatt and Katz, 1952; Katz, 1969). These random release events typically arise from fusion of a single synaptic vesicle that activates receptors at an individual postsynaptic site giving rise to miniature EPSCs or IPSCs (mEPSCs or mIPSCs). The capacity of mEPSCs and mIPSCs to report properties of neurotransmission at individual synapses has been instrumental in analysis of synaptic transmission as well as plasticity. At excitatory synapses in the CNS, spontaneous glutamate release activates NMDA and AMPA receptors, leading not only to electrical signaling but also to independent biochemical $\mathrm{Ca}^{2+}$-mediated signal transduction (McKinney et al., 1999; Sharma and Vijayaraghavan, 2003; Sutton et al., 2004, 2006, 2007; Espinosa and Kavalali, 2009; Lee et al., 2010). Furthermore, there is evidence that vesicles that drive these two modes of neurotransmission are supplied by different pools (Koenig and Ikeda, 1999; Sara et al., 2005; Wasser et al., 2007; Mathew et al., 2008; Chung et al., 2010) [but see Prange and Murphy (1999), Groemer and Klingauf (2007), Hua et al. (2010), and Wilhelm et al. (2010)]. For instance, earlier studies from our group demonstrated that a large

Received Oct. 5, 2010; revised Feb. 10, 2011; accepted Feb. 14, 2011.

Author contributions: Y.S., L.M.M., and E.T.K. designed research; Y.S., M.B., and M.A. performed research; Y.S., M.B., and E.T.K. analyzed data; Y.S., L.M.M., and E.T.K. wrote the paper.

This work was supported by a grant from the National Institute of Mental Health to E.T.K. E.T.K. is an Established Investigator of the American Heart Association. We thank Dr. Richard W. Tsien for initial advice about this project. We also thank Dr. Erika Nelson for her comments on the manuscript.

Correspondence should be addressed to Dr. Ege T. Kavalali, Department of Neuroscience, University of Texas Southwestern Medical Center, 5323 Harry Hines Boulevard, Dallas, TX 75390-9111. E-mail: Ege.Kavalali@ UTSouthwestern.edu.

DOI:10.1523/JNEUROSCI.5234-10.2011

Copyright $\odot 2011$ the authors $\quad 0270-6474 / 11 / 315378-05 \$ 15.00 / 0$ portion of spontaneously released vesicles are drawn from a pool other than the readily releasable pool that normally gives rise to evoked release (Sara et al., 2005; Virmani et al., 2005). More recently, Fredj and Burrone (2009) took advantage of a biotinylated version of synaptic vesicle protein synaptobrevin2/VAMP2 to mark recycling vesicles and showed that spontaneous release largely originates from the resting pool, which normally remains dormant during activity.

The differential regulation of spontaneous and evoked release may suggest a biological framework where synapses convey different types of information using the same channel. Consequently, this notion implies a postsynaptic mechanism that can distinguish these two signals originating from distinct vesicle pools. A recent study has provided evidence that spontaneous and evoked release activate non-overlapping populations of postsynaptic NMDA receptors (Atasoy et al., 2008). These experiments relied on (+)-5-methyl10,11-dihydro-5H-dibenzo[a,d]cyclohepten-5,10-imine maleate (MK-801), a use-dependent NMDA receptor antagonist (Huettner and Bean, 1988), to block NMDA receptors and revealed that complete blockade of spontaneous NMDA-mEPSCs left subsequent NMDA receptor-mediated responses to evoked neurotransmitter release unaffected. However, the majority of fast excitatory neurotransmission in the brain is performed by AMPA receptors, which also constitute the major current carrier during spontaneous transmission under physiological conditions (Espinosa and Kavalali, 2009). Additionally, activation of AMPA receptors by spontaneous glutamate release was shown to be necessary for maintenance of spines as well as postsynaptic signaling at rest (McKinney et al., 1999). Therefore, we evaluated whether AMPA receptor populations activated by spontaneous and evoked release show segregation similar to their NMDA receptor counterparts. To track the receptors 
involved in spontaneous or evoked neurotransmission, we used a polyamine agent, philanthotoxin (Washburn and Dingledine, 1996), that selectively blocks GluR2 subunit-deficient AMPA receptors in a use-dependent manner, and to increase philanthotoxin sensitivity of excitatory neurotransmission, we used GluR2-deficient mouse hippocampal neurons (Jia et al., 1996).

\section{Materials and Methods \\ Neuronal preparation}

Hippocampal neurons were isolated from wild-type and GluR2-deficient (GluR2-/-) mouse (Jia et al., 1996) pups of either sex at postnatal day 1-2 using previously described methods (Kavalali et al., 1999). Recordings were obtained from 2-week-old high-density hippocampal cultures, when synapses reach their functional maturity (Mozhayeva et al., 2002).

\section{Electrophysiology}

Cultured hippocampal cells were visualized with an inverted microscope (Zeiss Axiovert S100). Recordings were made in whole-cell voltageclamp mode and cells held at $-70 \mathrm{mV}$. Extracellular solution contained the following (in mM): $150 \mathrm{NaCl}, 4 \mathrm{KCl}, 2 \mathrm{MgCl}_{2}, 10$ glucose, $10 \mathrm{HEPES}$, and $2 \mathrm{CaCl}_{2}$, pH $7.4(310 \mathrm{mOsm})$. To isolate AMPA receptor currents induced by EPSCs, recordings were made in the presence of D-AP-5 (50 $\mu \mathrm{M})$ and picrotoxin (PTX; $50 \mu \mathrm{M}$ ), to block NMDA and GABA-activated currents, respectively. Spontaneous miniature EPSC (mEPSC) recordings were performed in the presence of tetrodotoxin (TTX) $(1 \mu \mathrm{M})$ in the external solution to suppress action potential firing. Philanthotoxin (Tocris Bioscience) was dissolved to its final concentration in the extracellular solution. Intracellular solution consisted of the following (in mM): 115 Cs- $\mathrm{MeSO}_{3}, 10 \mathrm{CsCl}, 5 \mathrm{NaCl}, 10$ HEPES, 0.6 EGTA, 20 tetraethylammonium-Cl, $4 \mathrm{Mg}-\mathrm{ATP}, 0.3 \mathrm{Na}_{2} \mathrm{GTP}$, and 10 lidocaine $\mathrm{N}$-ethyl bromide 2(triethylamino)- $\mathrm{N}$-(2,6-dimethylphenyl) acetamine (QX-314), pH 7.35 (300 mOsm; Sigma). Electrode tips had final resistances of 3-6 M $\Omega$. Currents were recorded with an Axopatch 200B amplifier and pClamp 9.0 software (Molecular Devices). Recordings were filtered at $2 \mathrm{kHz}$ and sampled at $10 \mathrm{kHz}$. Evoked EPSCs were elicited by rectangular pulses with $1 \mathrm{~ms}$ duration and $20-25 \mathrm{~mA}$ amplitude delivered via a constant current unit (WPI A385) through parallel platinum electrodes. This stimulation setting activates the majority of synaptic boutons formed on a neuron located between the electrodes (Atasoy et al., 2008). All statistical comparisons were performed with a two-tailed paired or unpaired $t$ test when appropriate. Cumulative histograms of mEPSC amplitudes were assessed using the Kolmogorov-Smirnov (K-S) test. All values are given as mean \pm SEM.

\section{Results}

\section{Philanthotoxin rapidly decreases mEPSC activity in}

GluR2-deficient hippocampal neurons

We used the polyamine compound philanthotoxin, a selective channel blocker of $\mathrm{Ca}^{2+}$-permeable AMPA receptors, as a pharmacological tool to confirm the predominance of GluR1 subunitcontaining AMPA receptors in hippocampal cultures prepared from constitutive GluR2 knock-out (GluR2-/-) mice. We monitored the miniature spontaneous EPSCs (mEPSCs) by holding the cells at $-70 \mathrm{mV}$ in the presence of TTX. Before the drug application, average spontaneous mEPSC frequency was $\sim 3 \mathrm{~Hz}$ in both cultures from wild-type and GluR2 knock-out mice, suggesting that GluR2 deficiency had a negligible impact on spontaneous neurotransmitter release rate. Application of philanthotoxin $(100 \mu \mathrm{M})$ reduced the mEPSC frequency in GluR2 - / - neurons but did not affect mEPSCs in cultures from wild-type animals (Fig. $1 A$ ). The kinetics of philanthotoxin block displayed two phases: first, a rapid reduction in frequency with a time constant of $19 \mathrm{~s}$, and second, a slower phase with a time constant of $\sim 300 \mathrm{~s}$ (Fig. $1 B$ ). Accordingly, charge transfer kinetics of AMPA-mEPSCs recorded from GluR2-deficient neurons showed a similar inhibition pattern with time constants of $\sim 16$
A
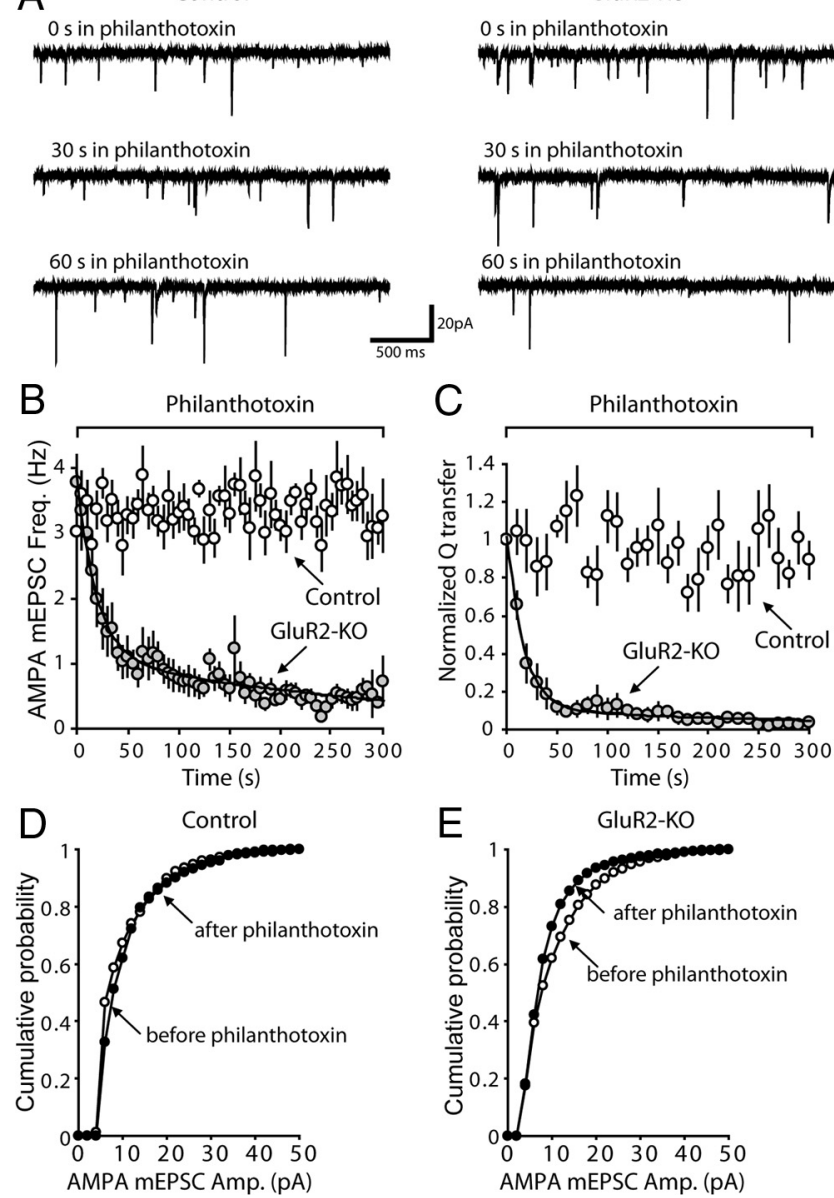

Figure 1. Philanthotoxin blocks spontaneous mEPSC activity only in neuronal cultures from GluR2-deficient mice. $A$, Representative traces of mEPSCs before and during $100 \mu \mathrm{m}$ philanthotoxin perfusion. $\boldsymbol{B}$, Philanthotoxin did not affect mEPSC frequency in wild-type neurons but significantly reduced $\mathrm{mEPSC}$ frequency in GluR2-deficient neurons during $5 \mathrm{~min}$ of drug perfusion. $m E P S C$ frequency is calculated as per second average of total number of events detected per 5 s. C, Charge transfer kinetics of spontaneous AMPA-mEPSCs in wild-type and GluR2deficient neurons during 5 min perfusion of philanthotoxin treatment. mEPSC data are quantified as charge transfer at 10 s intervals ( $n=7$ for each group). All error bars indicate SEM. $\boldsymbol{D}, \boldsymbol{E}$ The distribution of $m E P S C$ amplitudes showed a small but significant reduction after philanthotoxin application in GluR2-deficient synapses $(\boldsymbol{E})$ but not in control ones $(\boldsymbol{D})$.

and $\sim 240 \mathrm{~s}$ (Fig. 1C). On the other hand, philanthotoxin did not produce any alterations in mEPSC properties and frequency in cultures from the wild-type mice (Fig. $1 A, D$ ). These results demonstrate that the inhibition induced by philanthotoxin is due to its specific action on GluR2-lacking AMPA receptors. In the same experiments, the distribution of mEPSC amplitudes showed a small but significant reduction after philanthotoxin application in GluR2-deficient neurons but not their control counterparts (Fig. $1 D, E)(p<0.01, \mathrm{~K}-\mathrm{S}$ test) (see Fortin et al., 2010). Moreover, mEPSCs showed faster decay times (before philanthotoxin, $9.5 \pm 0.8 \mathrm{~ms}$; after philanthotoxin, $6.6 \pm 0.6 \mathrm{~ms} ; p<0.03 ; n=8$ ) consistent with open channel block. These findings imply that remaining mEPSCs after 5-min-long application of philanthotoxin were still philanthotoxin sensitive.

To further evaluate the contribution of philanthotoxininsensitive receptor populations to the AMPA-mEPSC activity remaining after philanthotoxin application, we applied philanthotoxin in the presence of $1 \mathrm{~mm}$ glutamate to block all surface receptors (Fig. $2 A$ ). This maneuver led to cessation of all mEPSC 


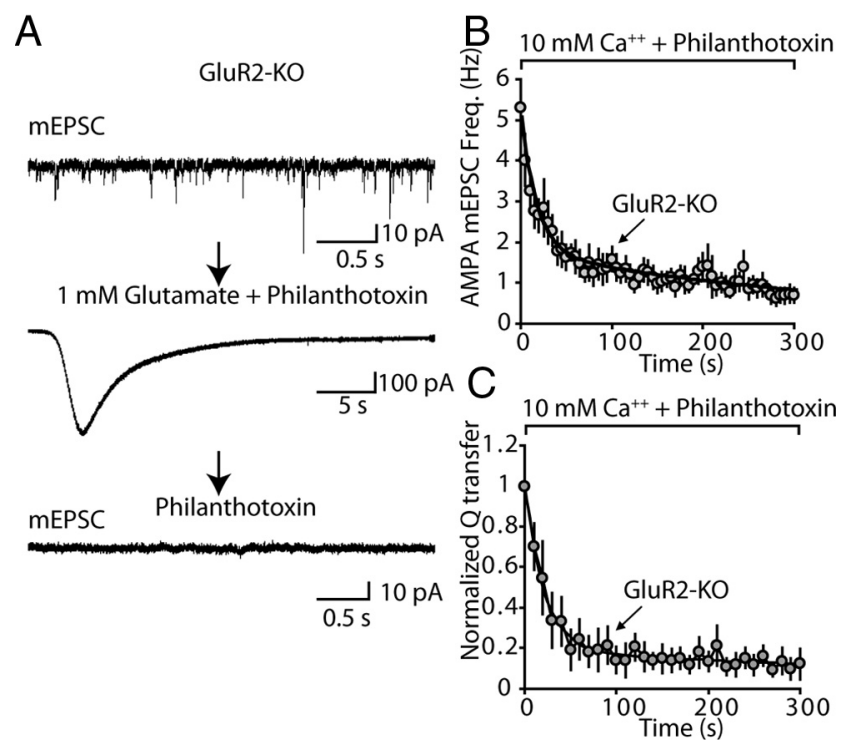

Figure 2. Complete block of AMPA-mEPSC activity after philanthotoxin application in the presence of extracellular glutamate. $A$, Application of philanthotoxin in the presence of $1 \mathrm{~mm}$ glutamate blocks all surface receptors and leads to cessation of all mEPSC activity $(n=4)$. $\boldsymbol{B}$, Philanthotoxin significantly reduced mEPSC frequency in GluR2-deficient neurons during $5 \mathrm{~min}$ of drug perfusion in the presence of $10 \mathrm{~mm} \mathrm{Ca}^{2+}$. C, Charge transfer kinetics of spontaneous AMPA-mEPSCs in GluR2-deficient neurons during 5 min perfusion of philanthotoxin treatment in the presence of $10 \mathrm{~mm}$ extracellular $\mathrm{Ca}^{2+}$. mEPSC data are quantified as charge transfer at 10 s intervals ( $n=8$ for each group). All error bars indicate SEM.

activity ( $n=4,4.1 \pm 1.3 \mathrm{~Hz}$ before philanthotoxin, no detectable mEPSCs after block in all experiments), thus corroborating the premise that all receptor populations are in principle philanthotoxin sensitive.

To address the possibility that the slow phase of philanthotoxin block originates from sites with extremely slow spontaneous release that otherwise possess philanthotoxin-sensitive receptor populations, we increased extracellular $\mathrm{Ca}^{2+}$ concentration to $10 \mathrm{~mm}$ to augment spontaneous release. Increase in extracellular $\mathrm{Ca}^{2+}$ concentration increases the rate of spontaneous neurotransmitter release detected electrophysiologically as well as optically at the level of individual synapses, even in sites with a low initial rate of spontaneous release (Sara et al., 2005; Atasoy et al., 2008). Interestingly, application of philanthotoxin in the presence of $10 \mathrm{mM} \mathrm{Ca}^{2+}$ did not give rise to a significantly different profile of block compared to the one seen in $2 \mathrm{mM} \mathrm{Ca}^{2+}$, although overall frequency of mEPSCs was augmented nearly twofold $\left(10 \mathrm{mM} \mathrm{Ca}^{2+}, 5.3 \pm 0.3 \mathrm{~Hz}, n=8\right.$ vs $2 \mathrm{mM} \mathrm{Ca}^{2+}, 3.7 \pm$ $0.4 \mathrm{~Hz}, n=8 ; p<0.02$ ) (Fig. $2 B, C$ ). This result indicates that the slow phase of philanthotoxin block likely originates from recruitment and mixing of unblocked receptor populations presumably via lateral diffusion of channels or receptor insertion into the postsynaptic membrane.

\section{Prior blockade of mEPSCs by philanthotoxin does not occlude subsequent evoked AMPA-eEPSCs}

Next, we aimed to assess the impact of philanthotoxin on evoked AMPA receptor-mediated EPSCs (AMPA-eEPSC). Here, after attaining stable evoked AMPA-eEPSC responses, we paused stimulation and perfused philanthotoxin onto the cultures. To eliminate AMPA receptor blockade as a result of spontaneous network activity present in $>2$-week-old cultures, philanthotoxin perfusion was preceded with TTX $(\sim 1 \mathrm{~min})$ treatment followed by philanthotoxin/TTX co-perfusion. Before the next
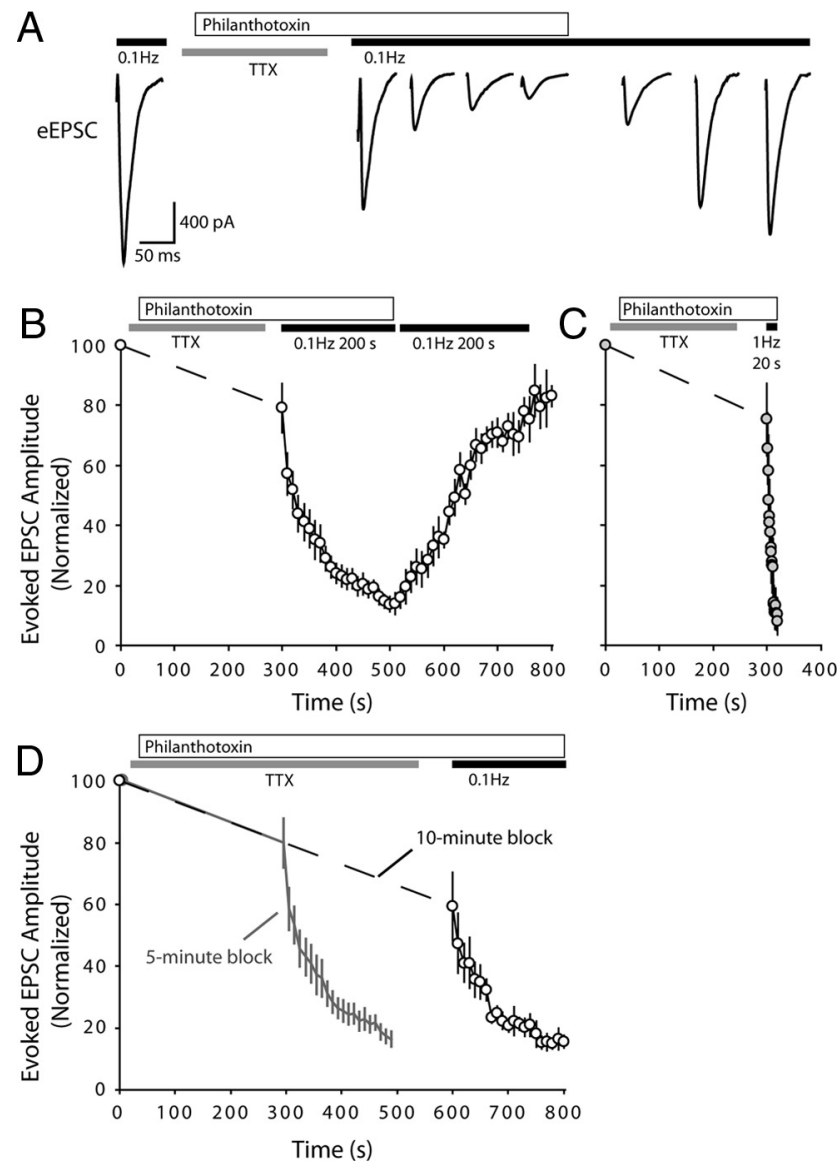

Figure 3. Five-minute philanthotoxin pretreatment causes a small reduction in the amplitude of the initial evoked AMPA-eEPSC in hippocampal cultures from GluR2-deficient mice. $\boldsymbol{A}$, Experimental protocol and examples of eEPSCs used to distinguish AMPA receptor pools involved in mEPSC and eEPSC activity. Evoked AMPA-EPSCs were recorded by applying $1 \mathrm{~ms}, 20$ $\mathrm{mA}$ pulses in the presence of $50 \mu \mathrm{M} \mathrm{AP5}$ and $50 \mu \mathrm{m}$ picrotoxin. $\boldsymbol{B}$, Following acquisition of baseline eEPSC responses, neurons were perfused with philanthotoxin and TTX for $5 \mathrm{~min}$. After removal of TTX and resuming stimulation, first eEPSC amplitude showed $\sim 20 \%$ reduction compared to the baseline value. Continued stimulation resulted in a swift reduction in eEPSC amplitudes. After removal of philanthotoxin from the perfusion medium, eEPSCs recovered to the baseline level in $300 \mathrm{~s}$ during continuing $0.1 \mathrm{~Hz}$ stimulation. C, A 10-fold increase in stimulation frequency yielded more robust reduction in eEPSC amplitude with a faster time course, supporting the use-dependent nature of philanthotoxin block of AMPA receptors. D, A $10 \mathrm{~min}$ pretreatment with philanthotoxin resulted in $\sim 40 \%$ reduction in first eEPSC amplitude. The gray and black lines depict the overlapping trends of $10 \mathrm{~min}$ and 5 min block achieved in separate philanthotoxin application experiments.

round of stimulation, we removed TTX from the bath (within 2 min) but continued the philanthotoxin perfusion. After 5 min of philanthotoxin treatment, evoked transmission was resumed at $0.1 \mathrm{~Hz}$, and the initial responses were found to be slightly less than those of the controls $(79 \pm 8.1 \% ; n=7)$ and progressively decayed to $13.7 \pm 2.5 \%$ within $200 \mathrm{~s}$ (Fig. $3 A, B$ ). Following removal of philanthotoxin, eEPSCs recovered up to $80 \%$ of their initial amplitudes within $250 \mathrm{~s}$ (Fig. 3B). These results indicate that the AMPA receptor pool blocked by philanthotoxin in the presence of TTX has minimal overlap with the receptor pool activated during evoked release.

To further evaluate the mixing of the two pools of AMPA receptors, we repeated these experiments with $10 \mathrm{~min}$ of philanthotoxin incubation at rest. The extent of block followed the same trend as the $5 \mathrm{~min}$ philanthotoxin application (compare the gray and black lines in Fig. 3D). At the end of the 10 min philanthotoxin treatment, the average amplitude of the first evoked re- 
sponse was $59.3 \pm 11 \%(n=6)$, and after $200 \mathrm{~s}$ of $0.1 \mathrm{~Hz}$ stimulation, it was reduced to $15.5 \pm 1.9 \%$ (Fig. $3 D$ ). Upon removal of philanthotoxin, responses recovered back to $80 \%$ of their initial levels (data not shown). The finding that philanthotoxin treatment for $10 \mathrm{~min}$ increases subsequent occlusion of evoked AMPA-eEPSCs may suggest that the two pools of receptors mix with a slow time course. However, this result may also be the result of philanthotoxin's block of AMPA receptors in a useindependent fashion. To verify use dependence of philanthotoxin action, we compared rate of block at two different stimulation frequencies. After $5 \mathrm{~min}$ of philanthotoxin incubation, we increased stimulation frequency 10 -fold $(1 \mathrm{~Hz})$, and at the end of $20 \mathrm{~s}$ of stimulation, eEPSC amplitude was found to be $7.9 \pm 4.4 \%$ of the control levels; however, reductions comparable to $0.1 \mathrm{~Hz}$ were achieved only after $200 \mathrm{~s}$ of stimulation (Fig. 3C). Therefore, as reported earlier (Washburn and Dingledine, 1996; Mainen et al., 1998), philanthotoxin inhibits GluR1-AMPA receptors in a use-dependent and reversible manner in our culture system.

\section{Discussion}

In this study, we used mice deficient in GluR2 subunits of AMPA receptors and quantitatively examined the impact of evoked and spontaneous neurotransmitter release on AMPA receptordependent glutamatergic signaling. These mice provided a unique setting to take advantage of polyamine compounds, such as philanthotoxin, that block GluR2-lacking AMPA receptors. In these experiments, sensitivity to philanthotoxin verified the dominance of GluR2-deficient receptor populations in this system. Moreover, philanthotoxin turned out to be a bona fide usedependent blocker of GluR2-lacking AMPA receptors, akin to MK-801 block of NMDA receptors (Mainen et al., 1998) and enabled us to examine the relationship between postsynaptic receptors activated by spontaneous and evoked release using usedependent block of unitary AMPA currents.

These studies provided three principle observations. First, philanthotoxin block of spontaneous AMPA-mEPSCs proceeded rapidly with a biphasic kinetic profile and decreased mEPSC frequency as well as mEPSC-mediated charge transfer within $5 \mathrm{~min}$. Second, the rapid block of AMPA-mEPSCs (to a level $<20 \%$ of the initial baseline activity) caused only very limited occlusion of the subsequent evoked AMPA-eEPSCs, which were reduced to $80 \%$ of their initial level. A 10 min perfusion of philanthotoxin decreased the level of subsequent AMPA-eEPSC amplitudes to $60 \%$, which remained substantially above the level of AMPAmEPSC block achieved within 5 min. Third, stimulation after removal of philanthotoxin resulted in a reversal of evoked AMPA-eEPSC block, verifying strict use dependence of philanthotoxin. These results are in agreement with observations on the differential MK-801-mediated block of NMDA-mEPSCs and NMDA-eEPSCs. However, there are also notable differences. The kinetics of use-dependent recovery from philanthotoxin block is faster than recovery from MK-801 block (Huettner and Bean, 1988; Atasoy et al., 2008). This property of philanthotoxin made testing occlusion of spontaneous AMPA-mediated neurotransmission by evoked release events unfeasible. Moreover, philanthotoxin block of spontaneous AMPA-mEPSCs triggered a more marked reduction in subsequent evoked AMPA-eEPSCs, suggesting that AMPA receptors activated in response to spontaneous and evoked release manifest more cross talk than their NMDA receptor counterparts. This observation is consistent with the higher mobility of AMPA receptors compared to NMDA receptors (Groc and Choquet, 2008). Faster mobility across the dendritic surface may lead to more rapid mixing of blocked and unblocked receptor populations. Experiments presented in Figure 2 further support this premise by indicating that the slow phase of mEPSC block seen during philanthotoxin application is likely due to mixing of blocked and unblocked receptor populations. Nevertheless, using philanthotoxin provided us with a critical advantage by enabling higher signal-to-noise measurements of decreases in mEPSC frequency in addition to charge transfer. In our earlier experiments, accurate estimation of NMDAmEPSC frequency was confounded by the inherent low signal-tonoise levels of these recordings (Atasoy et al., 2008).

These findings are also consistent with an alternative hypothesis that spontaneous release from a small population of terminals dominates the overall mEPSC activity and this population can be silenced swiftly by philanthotoxin with minimal impact on evoked EPSCs that originate from all synapses. Although this alternative remains plausible, optical imaging analysis of spontaneous release to date failed to uncover such a synaptic niche where a high level of spontaneous release dominates (Atasoy et al., 2008; Chung et al., 2010). Most optical studies to date agree that the sizes of synaptic vesicle pools giving rise to spontaneous and evoked release are correlated across synapses (Prange and Murphy, 1999; Sara et al., 2005; Groemer and Klingauf, 2007; Fredj and Burrone, 2009), although average spontaneous or evoked release rate per synapse may show significant variation (Atasoy et al., 2008).

These experiments rely on the modified genetic background of the GluR2-deficient mice, which presents a clear limitation to direct extrapolation of their results to wild-type synapses. Nevertheless, together with earlier work using genetically unmodified receptor populations on the segregation of NMDA receptormediated spontaneous and evoked synaptic responses, they make a cohesive case and provide several key implications. Most importantly, they indicate that the dichotomy we had observed earlier in NMDA receptor signaling was not due to a specific property of NMDA receptors but rather originates from distinct microdomains of evoked and spontaneous signaling (Sutton and Schuman, 2009). Similar segregation of NMDA receptor activation by evoked and spontaneous release also suggests that the observations we report here are not only specific to GluR2deficient receptors but are very likely to be applicable to GluR2containing receptors as well. These findings also argue against the possibility that potential differences between fusion pore kinetics or glutamate release profiles of spontaneous and evoked fusion events give rise to the differential activation of receptor populations. AMPA receptors have $\sim 100$-fold less affinity for glutamate than NMDA receptors. Therefore, in some cases, kinetics of fusion pore opening and the ensuing profile of glutamate release have been shown to favor activation of NMDA but not AMPA receptors (Renger et al., 2001; Choi et al., 2003). However, the parallels between use-dependent block of AMPA and NMDA receptors we observed here bolster the conclusion that segregation of spontaneous and evoked release stem from geometric differences in their respective sites of release rather than fusion pore properties.

These findings strengthen the possibility that certain disease conditions or signaling pathways may differentially affect AMPA receptor populations activated in response to evoked or spontaneous release (Pilpel et al., 2009) besides their selective impact on presynaptic mechanisms underlying the two forms of release (Wasser et al., 2007; Wasser and Kavalali, 2009; Nosyreva and Kavalali, 2010). In contrast to their implications for segregation of glutamatergic postsynaptic signaling, these results provide 
limited further insight into the actual microscopic topography of evoked and spontaneous release at the level of individual synapses. A large number of optical imaging studies suggest that spontaneous and evoked release originate from the same synaptic boutons (Prange and Murphy, 1999; Sara et al., 2005; Groemer and Klingauf, 2007; Atasoy et al., 2008; Fredj and Burrone, 2009). However, these studies cannot exclude the possibility that some synapses, particularly ones with release sites that cover $<0.2 \mu \mathrm{m}^{2}$ area (Atasoy et al., 2008), may harbor either spontaneous or evoked release. Mutually exclusive separation of spontaneous and evoked release into distinct synapses or active zones would render segregation of postsynaptic receptor populations a natural outcome (Zenisek, 2008). Nonetheless, optical imaging experiments to date (e.g., Atasoy et al., 2008) suggest that in a mature synaptic network only a small fraction $(<30 \%)$ of synaptic boutons maintain spontaneous or evoked release exclusively. It is important to note that the fraction of synaptic boutons that are solely capable of spontaneous release is much higher among immature synapses (Mozhayeva et al., 2002; Virmani et al., 2005). Therefore, higher-resolution imaging approaches as well as identification of specific markers for spontaneous release may uncover a larger fraction of such synapses within mature networks.

\section{References}

Atasoy D, Ertunc M, Moulder KL, Blackwell J, Chung C, Su J, Kavalali ET (2008) Spontaneous and evoked glutamate release activates two populations of NMDA receptors with limited overlap. J Neurosci 28:10151-10166.

Choi S, Klingauf J, Tsien RW (2003) Fusion pore modulation as a presynaptic mechanism contributing to expression of long-term potentiation. Philos Trans R Soc Lond B Biol Sci 358:695-705.

Chung C, Barylko B, Leitz J, Liu X, Kavalali ET (2010) Acute dynamin inhibition dissects synaptic vesicle recycling pathways that drive spontaneous and evoked neurotransmission. J Neurosci 30:1363-1376.

Espinosa F, Kavalali ET (2009) NMDA receptor activation by spontaneous glutamatergic neurotransmission. J Neurophysiol 101:2290-2296.

Fatt P, Katz B (1952) Spontaneous subthreshold activity at motor nerve endings. J Physiol 117:109-128.

Fortin DA, Davare MA, Srivastava T, Brady JD, Nygaard S, Derkach VA, Soderling TR (2010) Long-term potentiation-dependent spine enlargement requires synaptic $\mathrm{Ca}^{2+}$-permeable AMPA receptors recruited by CaM-kinase I. J Neurosci 30:11565-11575.

Fredj NB, Burrone J (2009) A resting pool of vesicles is responsible for spontaneous vesicle fusion at the synapse. Nat Neurosci 12:751-758.

Groc L, Choquet D (2008) Measurement and characteristics of neurotransmitter receptor surface trafficking. Mol Membr Biol 25:344-352.

Groemer TW, Klingauf J (2007) Synaptic vesicles recycling spontaneously and during activity belong to the same vesicle pool. Nat Neurosci $10: 145-147$

Hua Y, Sinha R, Martineau M, Kahms M, Klingauf J (2010) A common origin of synaptic vesicles undergoing evoked and spontaneous fusion. Nat Neurosci 13:1451-1453.

Huettner JE, Bean BP (1988) Block of N-methyl-D-aspartate-activated current by the anticonvulsant MK-801: selective binding to open channels. Proc Natl Acad Sci U S A 85:1307-1311.

Jia Z, Agopyan N, Miu P, Xiong Z, Henderson J, Gerlai R, Taverna FA, Velumian A, MacDonald J, Carlen P, Abramow-Newerly W, Roder J (1996) Enhanced LTP in mice deficient in the AMPA receptor GluR2. Neuron 17:945-956.

Katz B (1969) The release of neural transmitter substances, Vol 10. Liverpool: Liverpool UP.
Kavalali ET, Klingauf J, Tsien RW (1999) Activity-dependent regulation of synaptic clustering in a hippocampal culture system. Proc Natl Acad Sci U S A 96:12893-12900.

Koenig JH, Ikeda K (1999) Contribution of active zone subpopulation of vesicles to evoked and spontaneous release. J Neurophysiol 81:1495-1505.

Lee MC, Yasuda R, Ehlers MD (2010) Metaplasticity at single glutamatergic synapses. Neuron 66:859-870.

Mainen ZF, Jia Z, Roder J, Malinow R (1998) Use-dependent AMPA receptor block in mice lacking GluR2 suggests postsynaptic site for LTP expression. Nat Neurosci 1:579-586.

Mathew SS, Pozzo-Miller L, Hablitz JJ (2008) Kainate modulates presynaptic GABA release from two vesicle pools. J Neurosci 28:725-731.

McKinney RA, Capogna M, Dürr R, Gähwiler BH, Thompson SM (1999) Miniature synaptic events maintain dendritic spines via AMPA receptor activation. Nat Neurosci 2:44-49.

Mozhayeva MG, Sara Y, Liu X, KavalaliET (2002) Development of vesicle pools during maturation of hippocampal synapses. J Neurosci 22:654-665.

Nosyreva E, Kavalali ET (2010) Activity-dependent augmentation of spontaneous neurotransmission during endoplasmic reticulum stress. J Neurosci 30:7358-7368.

Pilpel Y, Kolleker A, Berberich S, Ginger M, Frick A, Mientjes E, Oostra BA, Seeburg PH (2009) Synaptic ionotropic glutamate receptors and plasticity are developmentally altered in the CA1 field of Fmrl knockout mice. J Physiol 587:787-804.

Prange O, Murphy TH (1999) Correlation of miniature synaptic activity and evoked release probability in cultures of cortical neurons. J Neurosci 19:6427-6438.

Renger JJ, Egles C, Liu G (2001) A developmental switch in neurotransmitter flux enhances synaptic efficacy by affecting AMPA receptor activation. Neuron 29:469-484.

Sara Y, Virmani T, Deák F, Liu X, Kavalali ET (2005) An isolated pool of vesicles recycles at rest and drives spontaneous neurotransmission. Neuron 45:563-573.

Sharma G, Vijayaraghavan S (2003) Modulation of presynaptic store calcium induces release of glutamate and postsynaptic firing. Neuron 38:929-939.

Sutton MA, Schuman EM (2009) Partitioning the synaptic landscape: distinct microdomains for spontaneous and spike-triggered neurotransmission. Sci Signal 2:pe19.

Sutton MA, Wall NR, Aakalu GN, Schuman EM (2004) Regulation of dendritic protein synthesis by miniature synaptic events. Science 304:1979-1983.

Sutton MA, Ito HT, Cressy P, Kempf C, Woo JC, Schuman EM (2006) Miniature neurotransmission stabilizes synaptic function via tonic suppression of local dendritic protein synthesis. Cell 125:785-799.

Sutton MA, Taylor AM, Ito HT, Pham A, Schuman EM (2007) Postsynaptic decoding of neural activity: eEF2 as a biochemical sensor coupling miniature synaptic transmission to local protein synthesis. Neuron 55:648-661.

Virmani T, Ertunc M, Sara Y, Mozhayeva M, Kavalali ET (2005) Phorbol esters target the activity-dependent recycling pool and spare spontaneous vesicle recycling. J Neurosci 25:10922-10929.

Washburn MS, Dingledine R (1996) Block of alpha-amino-3-hydroxy-5methyl-4-isoxazolepropionic acid (AMPA) receptors by polyamines and polyamine toxins. J Pharmacol Exp Ther 278:669-678.

Wasser CR, Kavalali ET (2009) Leaky synapses: regulation of spontaneous neurotransmission in central synapses. Neuroscience 158:177-188.

Wasser CR, Ertunc M, Liu X, Kavalali ET (2007) Cholesterol-dependent balance between evoked and spontaneous synaptic vesicle recycling. J Physiol 579:413-429.

Wilhelm BG, Groemer TW, Rizzoli SO (2010) The same synaptic vesicles drive active and spontaneous release. Nat Neurosci 13:1454-1456.

Zenisek D (2008) Vesicle association and exocytosis at ribbon and extraribbon sites in retinal bipolar cell presynaptic terminals. Proc Natl Acad Sci U S A 105:4922-4927. 